\title{
Bearing Capacity Assessment and Maintenance Scheme Optimization on a 220kV Transmission Tower with Foundation Settlement
}

\author{
Fengli Yang ${ }^{1, a}$, Chao ZHANG ${ }^{2, b}$, Binrong Zhu ${ }^{3, c}$ \\ ${ }^{1}$ China Electric Power Research Institute, Beijing, 100192, China \\ ${ }^{2}$ Shenyang Agricultural University, Shen Yang, 110870, China \\ ${ }^{3}$ China Electric Power Research Institute, Beijing, 100192, China \\ ayangfl1@epri.sgcc.com.cn, ${ }^{b}$ zhang229592485@163.com, czhubinrong@epri.sgcc.com.cn
}

Keywords: transmission tower; foundation settlement; stress ratio; assessment; staying wire.

\begin{abstract}
Finite element model of a $220 \mathrm{kV}$ transmission tower was established in general software ANSYS. The constrained method of the freedoms of tower foots with foundation settlements was proposed. According to the monitoring data of the non-uniform settlement, the relative settlement values were applied at the tower foots as displacement loads. By considering the relative position relationship between the wind direction and the settlement direction, the foundation settlement case can be combined with the design wind load case and the design ice load case, and structural analysis of the transmission tower totally includes 32 cases. The stresses of the main members and diagonal members at the tower head and tower body were calculated and assessed for different load cases. Optimization on the angle between staying wire and the ground was carried out. The reducing efficiency of stresses by using staying wires for two angles between the staying wires and the ground was compared.
\end{abstract}

\section{Introduction}

Effected by the surface settlement of the goaf, the foundation of the transmission pole and tower will be destroyed by settlement, inclination or slip [1-4]. Then with the variation of the leg opening and height difference of the transmission tower legs, the transmission tower structures will bear high additional loads, and part body or whole body of the tower structure may break down [6-9]. Deformations of the foundation have brought serious threat to the safe operation of the power grid.

Limited values of the uniform foundation settlement for the towers with different heights are specified in the design technical regulations. Limited values for foundation with non-uniform settlement, inclination and slip aren't specified. The healthy state evaluation of the tower with foundation deformation hasn't been researched sufficiently. Prototype test on the transmission tower with foundation deformation is very costly and difficult to be realized. It is necessary to analyse the member forces of the transmission tower with foundation settlement. In this paper, finite element model of a $220 \mathrm{kV}$ transmission tower was established in general software ANSYS. The constrained method of the freedoms of tower foots with foundation settlements was proposed. By considering the relative position relationship between the wind direction and the settlement direction, the foundation settlement case can be combined with the design wind load case and the design ice load case, and structural analysis of the transmission tower totally includes 32 cases. The stresses of the main members and diagonal members at the tower head and tower body were calculated for different load cases, which can bring technical suggestions for the maintenance scheme of the transmission towers with foundation settlements. Optimization on the angle between staying wire and the ground was carried out. 


\section{Analysis model}

A $220 \mathrm{kV}$ tangent transmission tower is selected for the structural analysis with foundation settlement. Bearing capacity of the tower agrees with the requirement of the working load cases including wind load, accreted ice load and installation load etc. The design wind velocity is $30 \mathrm{~m} / \mathrm{s}$ at $15 \mathrm{~m}$ reference height and the design ice thickness is $10 \mathrm{~mm}$. Total height of the tower is $58.5 \mathrm{~m}$. The vertical and horizontal spans of conductors and ground wires are $175 \mathrm{~m}$ and $225 \mathrm{~m}$, respectively. The type of the conductor and the ground wire is $2 \times$ LGJQ-240 and GJ-70. The outlines of the transmission tower are presented in Fig.1.

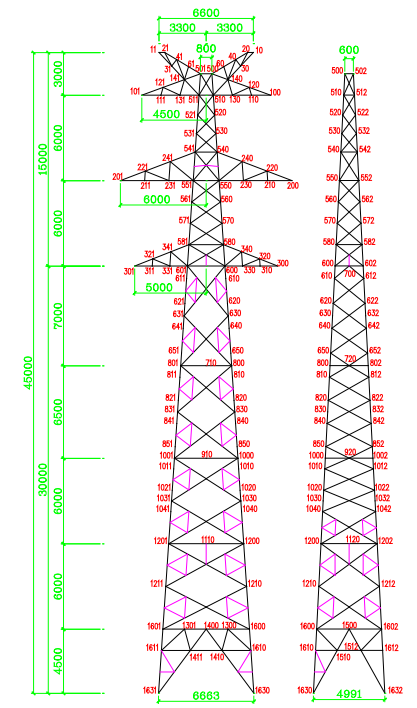

Fig.1 Outlines of the transmission tower

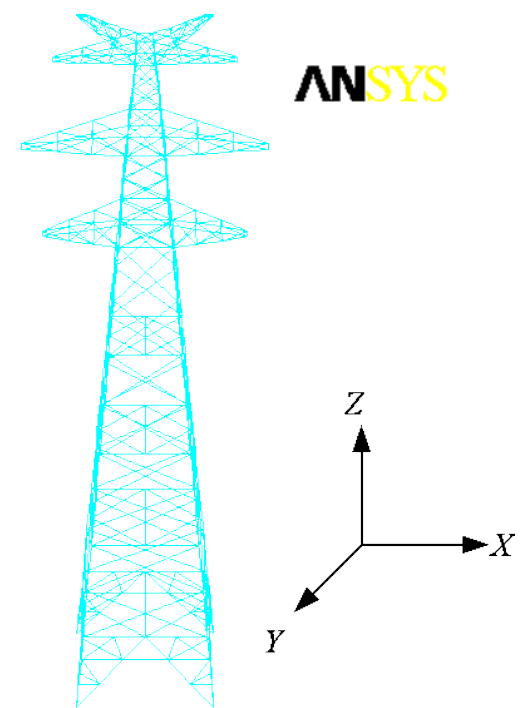

Fig.2 FEA model

The general FEA software ANSYS was applied for the tower structural analysis with foundation settlement. The leg members and the main members of the tower are simulated by BEAM4 element. The diagonal members are simulated by LINK8 element [8-9]. The secondary members are ignored in the FEA model. The connection between the main members and the diagonal members is hinged. The finite element analysis (FEA) model of the transmission tower and the global coordinate system are shown in Fig.2. Tower foot numbers and the wind directions are illustrated in Fig.3. The absolute settlement values, the relative settlement values as well as the constrained conditions in FEA model are listed in Table 1. The non-uniform settlement case is illustrated in Fig.4. For the non-uniform settlement of foundation, one of the four tower foots is fixed, the other three foots are settled by the relative settlement values in Table 1.

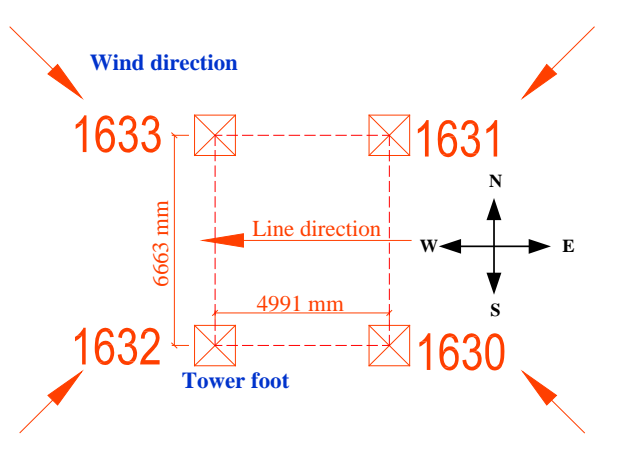

Fig.3 Tower foot numbers and the wind directions

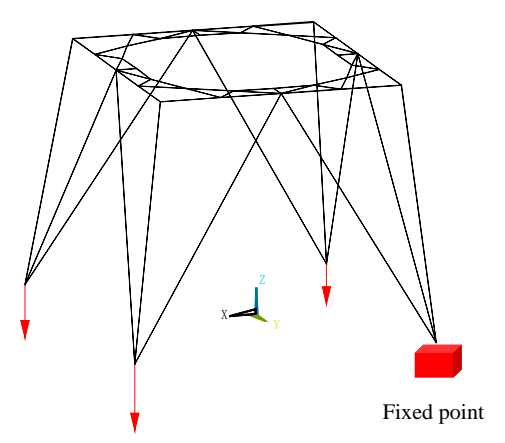

Fig.4 Illustration of non-uniform settlement 
Table 1 Settlement values and the constrained conditions

\begin{tabular}{|c|c|c|c|c|c|}
\hline $\begin{array}{c}\text { Tower foot } \\
\text { numbers }\end{array}$ & $\begin{array}{c}\text { Absolute settlement } \\
\text { values }(\mathrm{m})\end{array}$ & $\begin{array}{c}\text { Relative settlement } \\
\text { values }(\mathrm{m})\end{array}$ & UX & UY & UZ \\
\hline 1630 & -0.186 & -0.052 & Fixed & Fixed & Released \\
\hline 1631 & -0.153 & -0.019 & Fixed & Fixed & Released \\
\hline 1632 & -0.162 & -0.028 & Fixed & Fixed & Released \\
\hline 1633 & -0.134 & 0 & Fixed & Fixed & Fixed \\
\hline
\end{tabular}

\section{Analysis cases}

Wind loads and accreted ice loads are frequent load types for the transmission lines. By considering the relative position relationship between the wind direction and the settlement direction, the total number of the analysis cases is 32, and illustration of the cases is shown in Fig.5. The analyses are focused on the foundation settlements, which are combined with the working load cases of 0-degree wind, 45egree wind, 60-degree wind, 90-degree wind and $10 \mathrm{~mm}$ accreted ice load.

In reference [8], it shows that when the settlement value is in the range of 0 to $100 \mathrm{~mm}$, deformation of the tower body is relatively small, and the additional moment induced by the deformation of the tower body can be ignored. Large deformation effect has little influence on the member forces of the tower with foundation settlement. The maximum relative settlement value in Table 1 is $52 \mathrm{~mm}$. Therefore, the large deformation effect was ignored in the structural analysis in this study.

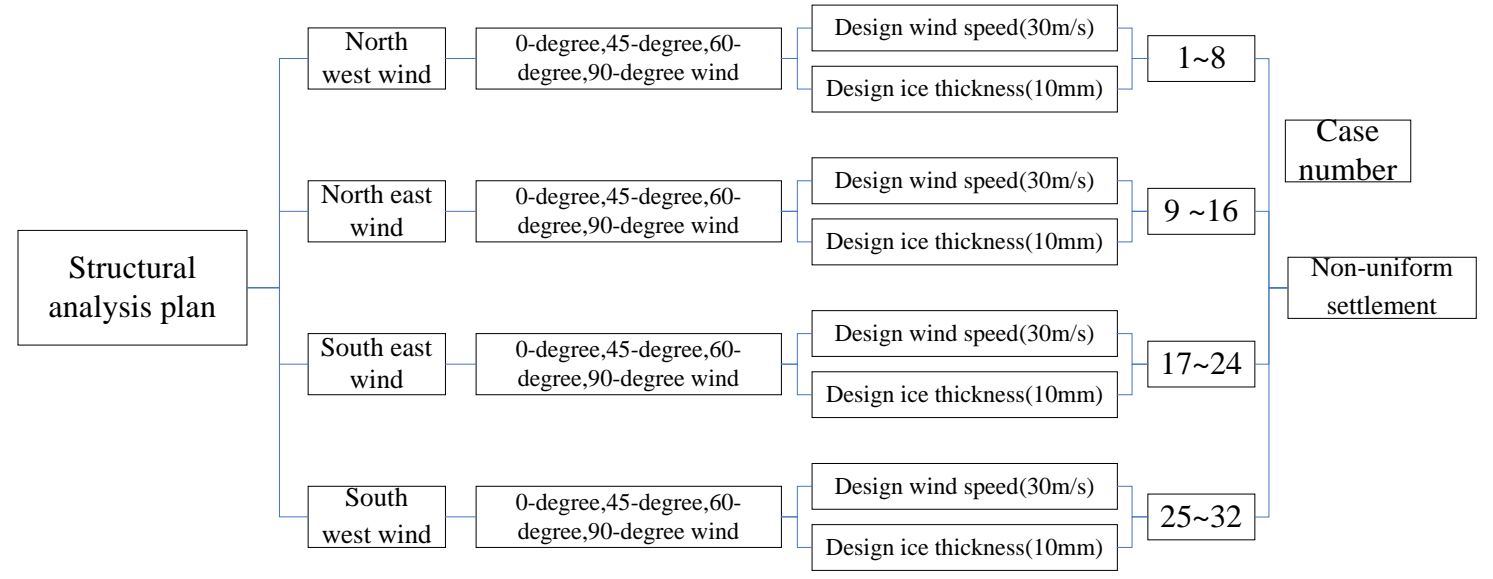

Fig.5 Illustration of analysis cases

\section{Structural analysis of transmission tower with settlement}

The structural analysis of the transmission tower under 32 load cases were carried out. The displacements and the axial forces of the transmission tower were obtained. When the wind direction is north-east and the wind incidence angle is 90 degrees (load case number 4), the displacement distribution of the transmission tower for wind load case and accreted ice load case are shown in Fig.6 (a) and Fig.6 (b), respectively. 


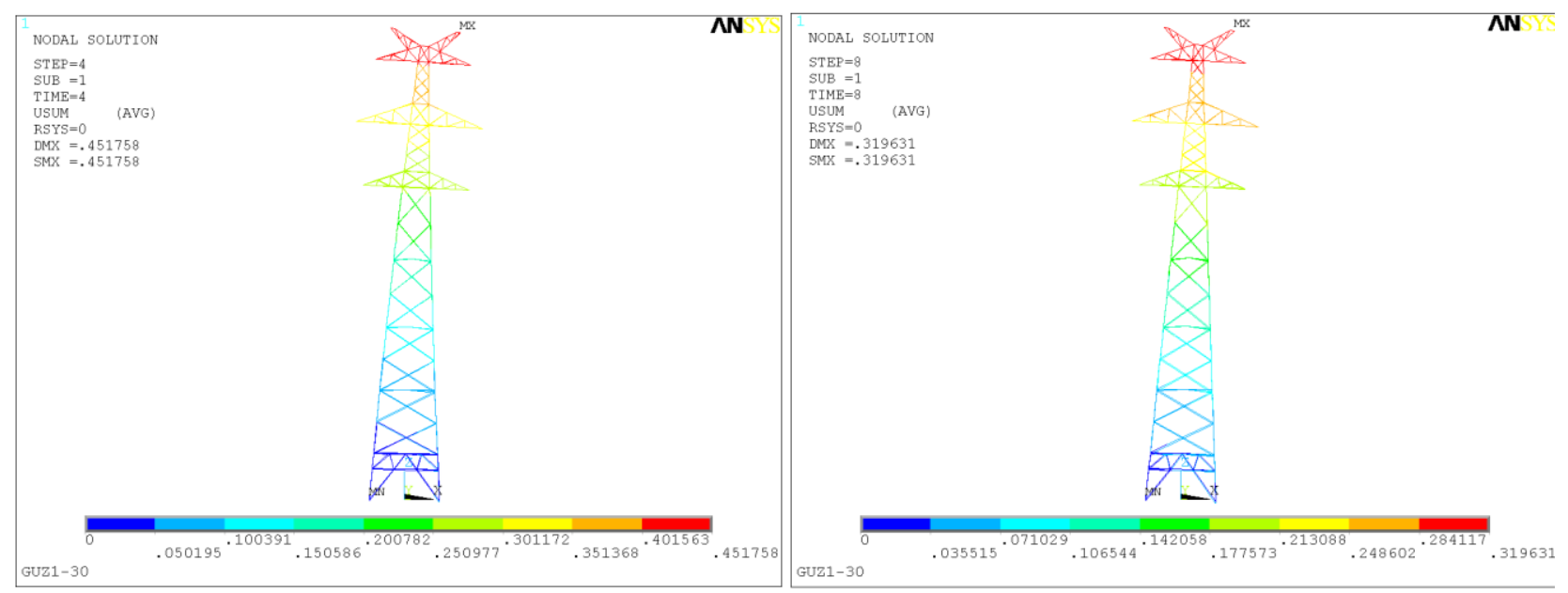

(a) Wind load case

(b) Accereted ice load case

Fig.6 Displacement distribution under the load case 4(Unit: m)

The finite element analysis (FEA) method considering the specifications in [10] is used for the structural analysis of the towers with foundation deformation, and the stress state of the towers is estimated according to the FEA results. Stresses and stress ratios of the tower members can be calculated according to the formulas in [10] based on the axial forces from ANSYS analysis. Stress ratio is the ratio of real stress to the design stress. It is assumed that the member would be destroyed when its stress is higher than the design stress, which can also be identified by the stress ratio is larger than 1.0. The buckling failure state can be considered by stability coefficient of steel members. The bearing capacity of tower members under compressed load can be checked by Eq.1.

$$
\frac{N}{\varphi A} \leq m_{N} f
$$

where $\varphi$ is the stability factor of the compressed member, $A$ is the gross sectional area of the member, $f$ is the design strength of the steel. $m_{N}$ is the reduction factor of the compressed member, which is related to the ratio of the flange length to the thickness.

According to on the analysis results, it can be found that the stresses of the members at the tower head and the cross arms are basically not changed during foundation settlement. The diagonal members at the tower body changes by a very small extent and the maximum stress ratio of the diagonal members is 0.85 . The main members of the tower body especially near the tower foots are sensitive to the foundation settlement, and the stress variations of these main members were discussed as follows.

For the main member stresses with and without foundation settlement, the control wind incidence angle is 45-degree. For the main members near the tower foots, the main member stress increase by some extents. As for the main members are far from the foot points, the varying extents will be decreased and even no changes occur. The main member stresses and stress ratios with and without foundation settlement were listed in Table 2. Only the maximum stress and the corresponding load case were selected for comparison. Before foundation settlement, the maximum stress ratio of the main members at tower body was only about 0.84 . The main member stress ratios increase after foundation settlement and the maximum value is about 0.90 . The bearing capacity still meets well with the requirements. 
Table 2 Main member stresses and stress ratios with and without foundation settlement

\begin{tabular}{|c|c|c|c|c|c|c|}
\hline \multirow{2}{*}{$\begin{array}{l}\text { Number of } \\
\text { main } \\
\text { members }\end{array}$} & \multicolumn{2}{|c|}{ Without settlement } & \multicolumn{3}{|c|}{ With settlement } & \multirow{2}{*}{$\begin{array}{c}\text { Variation } \\
(\%)\end{array}$} \\
\hline & Stress(MPa) & $\begin{array}{c}\text { Stress } \\
\text { ratio }\end{array}$ & Stress(MPa) & Load case number & $\begin{array}{c}\text { Stress } \\
\text { ratio }\end{array}$ & \\
\hline $1000-1010$ & -236.6 & 0.76 & -241.7 & $10 / 26$ & 0.78 & 2.23 \\
\hline $1010-1020$ & -241.6 & 0.78 & -248.3 & $10 / 26$ & 0.80 & 2.82 \\
\hline $1020-1030$ & -247.7 & 0.80 & -255.9 & $10 / 26$ & 0.83 & 3.38 \\
\hline $1030-1040$ & -256.1 & 0.83 & -267.3 & $10 / 26$ & 0.86 & 4.36 \\
\hline $1040-1200$ & -260.6 & 0.84 & -273.5 & $10 / 26$ & 0.88 & 4.88 \\
\hline $1200-1210$ & -234.2 & 0.76 & -252.6 & $10 / 26$ & 0.82 & 7.95 \\
\hline $1210-1600$ & -249.8 & 0.81 & -278.7 & $10 / 26$ & 0.90 & 11.54 \\
\hline $1600-1610$ & -209.8 & 0.68 & -237.6 & $10 / 26$ & 0.77 & 13.88 \\
\hline $1610-1630$ & -206.4 & 0.67 & -235.0 & $10 / 26$ & 0.76 & 13.81 \\
\hline
\end{tabular}

\section{Optimization on the angle between the staying wire and the ground}

In order to ensure the safety of the transmission tower with foundation settlement, two maintenance schemes are usually considered. The first is installing staying wires at the tower body. The second is rebuilding a new tower and applying the large panel foundation. For the first scheme, the reinforced efficiency is related to many parameters such as the height of the suspension point, the initial tension of the staying wires as well as the angle $\alpha$ (in Fig.7) between the staying wire and the ground. According to the past research works, it show that the angle $\alpha$ between the staying wire and the ground is very important for the reinforced efficiency of the stresses of tower members with foundation settlement. Therefore the optimization analysis on the angle $\alpha$ was carried out.

According to the design experiences of the design department, four GL-100 staying wires were installed. The staying wire was simulated by LINK10 cable element in ANSYS. By considering the environmental constraint surrounding the transmission tower with foundation settlement, the angle $\alpha$ between the staying wire and the ground should not lower than 45 degrees. The wind direction was assumed in North West direction. When $\alpha$ is 60 degrees and 70 degrees respectively, the stress ratios of the tower members were calculated by FEA analysis. The calculated results are listed in Table 3 . It can be seen that the stress ratios of tower members can be reduced significantly after reinforced by using staying wires. The variation of stress ratios for $\alpha$ is 60 degrees is larger than those for $\alpha$ is 70 degrees. It indicates that the reducing amplitudes of the stress ratios are decreased with the increasing the angle $\alpha$ between the staying wire and the ground.

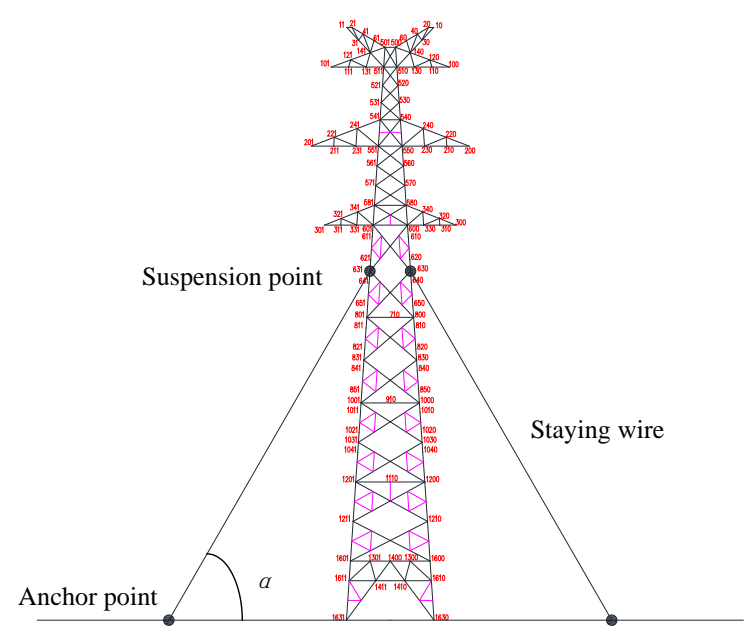

Fig.7 Illustration of the foundation maintenance by staying wires 
Table 3 Stress ratios with and without staying wires

\begin{tabular}{|c|c|c|c|c|c|}
\hline \multirow{2}{*}{$\begin{array}{c}\text { Number of } \\
\text { main members }\end{array}$} & \multirow{2}{*}{$\begin{array}{c}\text { Without } \\
\text { staying wires }\end{array}$} & $\begin{array}{c}\text { With staying } \\
\text { wires }\end{array}$ & $\begin{array}{c}\text { Variation } \\
(\%)\end{array}$ & $\begin{array}{c}\text { With staying } \\
\text { wires }\end{array}$ & $\begin{array}{c}\text { Variation } \\
(\%)\end{array}$ \\
\hline $640-650$ & 0.66 & 0.60 & -10.09 & 0.62 & -6.63 \\
\hline $650-800$ & 0.69 & 0.61 & -11.08 & 0.64 & -7.14 \\
\hline $800-810$ & 0.64 & 0.55 & -13.62 & 0.59 & -8.45 \\
\hline $850-1000$ & 0.74 & 0.60 & -18.98 & 0.66 & -11.31 \\
\hline $830-1001$ & 0.51 & 0.40 & -21.06 & 0.46 & -9.84 \\
\hline $810-822$ & 0.54 & 0.28 & -46.92 & 0.42 & -22.43 \\
\hline $1000-1010$ & 0.75 & 0.61 & -18.88 & 0.66 & -12.05 \\
\hline $1040-1200$ & 0.80 & 0.69 & -13.89 & 0.71 & -10.89 \\
\hline $1020-1042$ & 0.58 & 0.40 & -31.14 & 0.48 & -16.26 \\
\hline $1200-1210$ & 0.70 & 0.64 & -8.76 & 0.66 & -5.75 \\
\hline $1200-1211$ & 0.84 & 0.78 & -7.30 & 0.81 & -3.47 \\
\hline $1210-1602$ & 0.76 & 0.61 & -19.60 & 0.68 & -10.07 \\
\hline
\end{tabular}

\section{Summary}

Finite element model of a $220 \mathrm{kV}$ transmission tower was established. The relative settlement values were applied at the tower foots as displacement loads. The stresses of the main members and diagonal members at the tower head and tower body were calculated for 32 load cases. The reducing efficiency by using staying wires for two angles between the staying wires and the ground was compared. Three main conclusions are as follows.

(1)Before and after foundation settlement, the stresses of the members at the tower head and the cross arms are basically not changed. The diagonal members at the tower body changes by a very small extent and the maximum stress ratio of the diagonal members is 0.85 .

(2)For the stresses of main members, the control wind incidence angle is 45-degree. The stress ratios of main member increase after foundation settlement and the maximum value is about 0.90 . The bearing capacity still meets well with the requirements.

(3)The reducing amplitudes of the stress ratios are decreased with the increasing the angle $\alpha$ between the staying wire and the ground. The angle $\alpha$ of 60 degrees was proposed for the maintenance of the $220 \mathrm{kV}$ transmission tower with foundation settlement.

\section{Acknowledgement}

The authors acknowledge the financial support provided by the science and technology projects of State Grid Corporation of China (Dynamic characteristics and ultimate behavior of lattice tower in the mining area).

\section{References}

[1] Zhang Jianqiang, Yang kun, Wang Yudong, et al: Research on foundation treatment of high voltage transmission towers erected above goaf of coal mine, Power System Technology 30(2) (2006),p.30-34.

[2] Qin Qingzhi, Cao Yujie, Mao Tongyu, et al: Design study of UHV line tower foundation in areas affected by coal mining excavation, Electric Power Construction 30(2)(2009),p.18-21.

[3] Liu Yuchuan, Liu Zude. Study on stabilization and rectification technology for inclined transmission tower, Rock and Soil Mechanics 29(1) (2008),p.173-176. 
[4] Yuan Guanglin, Zhang Yunfei, Chen Jianwen, et al: Reliability assessment of transmission tower in mining subsidence area, Power System Technology 34(1) (2010),p.214-218.

[5] Yuan Guanglin, Chen Jianwen, Yang Gengyu, et al: Influence of dynamic ground deformation on internal force and structural deformation of transmission towers, Journal of Hehai University 38(3) (2010),p.284-289.

[6] Sun Dongming, Xia Wujun, Chang Hongfei: Research on structural behavior of transmission line tower due to underground mining, Journal of Wuhan University of Technology 32(10) (2010),p.58-61.

[7] Sun Dongming: Study on mechanic model of transmission line steel tower and interaction mechanism of tower-line system located at mining area. Xuzhou: China University of Mining and Technology(2010).

[8] Fengli Yang, Jingbo Yang, Junke Han, et al: Study on the limited values of foundation deformation for a typical UHV transmission tower, IEEE Transactions on Power Delivery 25(4) (2010),p.2752-2758.

[9] Fengli Yang, Qinghua Li, Jingbo Yang, et al: Assessment on the stress state and the maintenance schemes of the transmission tower above goaf of coal mine, Engineering Failure Analysis 31(2013),p.236-247.

[10] National Economy and Trade Commission: DL/T 5154-2012, Technical regulation of design for tower and pole structures of overhead transmission line. Beijing: China Electric Power Press(2012). 